\title{
Research on Acoustic Emission Characteristics and Constitutive Model of Rock Damage Evolution with Different Sizes
}

\author{
Haijiang Zhang, ${ }^{1,2}$ Xiaohu Zhang $\mathbb{D}^{3}{ }^{3}$ and Hongbo Zhou ${ }^{4}$ \\ ${ }^{1}$ School of Civil Engineering, Shaoxing University, Shaoxing 312000, China \\ ${ }^{2}$ Key Laboratory of Rock Mechanics and Geohazards of Zhejiang Province, Shaoxing 312000, China \\ ${ }^{3}$ School of Civil Engineering, Guizhou University of Engineering Science, Bijie 551700, China \\ ${ }^{4}$ Nonferrous Geological Exploration and Research Institute Limited Liability Company, Shenyang 110013, China \\ Correspondence should be addressed to Xiaohu Zhang; zhangxiaohucumtb@163.com
}

Received 4 November 2020; Revised 16 November 2020; Accepted 18 November 2020; Published 29 November 2020

Academic Editor: Qian Yin

Copyright (c) 2020 Haijiang Zhang et al. This is an open access article distributed under the Creative Commons Attribution License, which permits unrestricted use, distribution, and reproduction in any medium, provided the original work is properly cited.

\begin{abstract}
In this study, considering the scale effect of rock mass, the influence of different height-to-diameter ratios on rock mechanics and acoustic emission characteristics was studied by using PFC2D software. The damage constitutive model of rock was established, and the damage evolution characteristics of rock with different height-to-diameter ratios were further analyzed. The results showed that, with the increase of height-to-diameter ratio $K$, the uniaxial compressive strength and peak strain of rock exhibited a gradual decrease; however, the elastic modulus gradually increased. Moreover, rock failure modes exhibited different characteristics under different $K$ values. The scale effect showed little influence on the acoustic emission characteristics in the elastic stage; nonetheless, in the plastic deformation stage and the residual damage stage, with the increase of the rock's height-to-diameter ratio, the maximum number of impacts of acoustic emission increased, the range of strong strain of acoustic emission decreased, and the maximum time of acoustic emission impacts increased gradually. The height-to-diameter ratio of the rock slightly influenced the zero-damage stage of the rock, but the damage affecting the rock increased slowly and accelerated the development stage. The damage evolution law was found to be similar when the $K$ values varied from 1.0 to 2.0 ; however, when the $K$ was greater than 2.0, the damage evolution law exhibited the characteristics of slowing down in the acceleration phase.
\end{abstract}

\section{Introduction}

With the development of economy and the increase of the expansion scale of underground space in China, the geological disasters related to rock mass instability, such as tunnel rock burst and mine rock burst, are becoming progressively more serious [1-10]. Rock is a combination of various mineral particles bonded naturally with a bonding substance. When an external force is applied, the bonding between the rock particles gets damaged and destroyed, eventually leading to the formation of macroscopic texture defects, which promote the rock instability damage [11-15]. Treatment of the mechanical properties of rocks not only is related to the mechanical environment, but also exhibits a strong size effect [16]. Till date, significant research efforts have been devoted to the study on the size effect of rock mechanics. For example, Wang et al. [17] conducted uniaxial compressive strength tests on marble, diorite, and tuff with different aspect ratios. The test results showed that, with the increase of aspect ratio, the compressive strength of rock showed the trend of first decreasing and then increasing. Liang et al. [18] believed that the size effect of rock mass includes the size effect of intact rock mass and the size effect of jointed rock mass, but there is no organic connection between them. Therefore, they proposed a multi-scale rock mass engineering calculation method at the micro level and the macro level and established a relationship between the two scale effects. Moreover, Yang et al. [19] analyzed the characteristic relationship between rock unit failure, elastic modulus change, and rock size and established a statistical constitutive equation for rock damage in uniaxial compression considering the size characteristics. Zhang et al. 
[20] used separated Hopkinson pressure bars to carry out cyclic impact tests on granite samples with different heightto-diameter ratios, in order to explore the cyclic dynamic characteristics of rocks and their size effects. Hong et al. [21] comprehensively analyzed the anisotropic distribution of structural surfaces at different scales and proposed an anisotropic coefficient of variation AVC3D considering the three-dimensional (3D) topographic parameters of orthogonal directions. Fu [22] believed that, with the increase of the height-to-diameter ratio, the uniaxial compressive strength of the rock first decreased, then increased, and then tended to be stable. Its fracture form also changed from complex split failure to shear failure. The above-mentioned studies are of great significance for understanding the damage characteristics of rocks under different scale conditions; nonetheless, the size effect of rock mechanics properties is of great complexity, which is still a subject worthy of further study at present.

At the same time, the process of rock fracture is often accompanied by acoustic emission phenomenon [23-26]. In practical engineering, the stability of rock mass is often monitored by analyzing the characteristics of acoustic emission [27]. Accompanying the size effect of rock mechanics, the acoustic emission characteristics of rocks should also have different characteristics; however, research in this area has rarely been reported. Based on this, herein, first different height-to-diameter ratios were considered by using the numerical simulation software, namely, the particle flow code in two dimensions (PFC2D) $[28,29]$ to study and analyze the rock mechanics and acoustic emission characteristics, and then a rock damage constitutive model was constructed based on the acoustic emission characteristics. Furthermore, the rock at different scale law of damage evolution was analyzed. The research results have certain significance for further understanding the size effect of rock mechanics and preventing and controlling rock engineering disasters.

\section{Uniaxial Particle Flow Model of Rock with Different Scales}

2.1. Basic Principles of Particle Flow. In the PFC2D particle flow method, the cells are mainly in the form of 2D circular particles and walls, both of which are rigid and non-deformable; nonetheless, they can overlap each other when they are in contact. In the PFC2D calculation cycle, the force between particles mainly follows Newton's second law and force-displacement law, thus simulating the relationship among contact, motion, and interaction between particles. The contact force between the particles was updated by using the force-displacement law, and the position of the particles and the boundary was sought by using Newton's law of motion to form a new contact (Figure 1). In the discrete element PFC2D particle flow model, the macroscopic mechanical characteristics of the rock are realized in terms of the simple constitutive relationship of each contact. The contact constitutive model of particles consists of the following three parts: stiffness model, sliding model, and bonding model.
The contact bonding model is divided into point bonding model and parallel bonding model. For simulation of rock materials, a bonding model is required between the particles in contact, which actually represents the bonding strength between the rocks (Figure 2). When the point bonding model is used, the contact stiffness is still effective as long as the particles remain in contact, regardless of whether the bonding is damaged or not; however, this result is inconsistent with the fracture mechanism of the rock. When the parallel bonding model is used, the contact stiffness and the bonding stiffness together constitute the macroscopic stiffness, and the bonding fracture immediately leads to the decrease of the macroscopic stiffness. Therefore, in this study, the parallel bond model was employed, which could simulate rock-like materials more realistically by using parallel bonding during tensile or shear fracture.

\subsection{Verification of Physical and Mechanical Parameters of} Rock. In particle flow programs, uniaxial compression trialand-error method is generally used to adjust the mesoscopic parameters of the established model through comparative analysis and verification between a large number of numerical tests and laboratory tests [30]. In this study, through the indoor sandstone experiment, uniaxial compression numerical simulation was carried out with the same size $(60 \mathrm{~mm} \times 120 \mathrm{~mm})$ and other parameters. The parameters were tested and checked repeatedly by trial-and errormethod, and the microparameters that could reflect the physical and mechanical properties of sandstone were thus obtained (Table 1). The stress-strain curve of the particle flow model (Figure 3) is in good agreement with the results of the laboratory tests.

2.3. Particle Flow Code Rock Models of Different Scales. In order to analyze the impact of size effect on rock mechanics and acoustic emission characteristics, four different numerical specimens of rock with high aspect ratio (Figure 4) were established, with a fixed diameter of $50 \mathrm{~mm}$ and an aspect ratio $K$ of $1.0,1.5,2.0$, and 2.5, respectively. The effects of particle shape and particle distribution were not considered in each model, and the parameters listed in Table 1 were adopted uniformly. The total number of particles generated by each model was $4358,6560,8753$, and 10,946, respectively. During the test, the external force was applied through the displacement control mode of the wall, and the loading speed was $0.02 \mathrm{~m} \mathrm{~s}^{-1}$. In order to ensure that the test results are not affected by the degree of the test, the same model test stop threshold was set through FISH language, and the simulation test was considered to be completed when the residual stress after the peak of the model was equal to 0.01 times the peak stress.

\section{Influence of Size Effect on Rock Mechanics and Acoustic Emission Characteristics}

3.1. Relationship between Rock Size and Mechanical Strength. The stress-strain curves of the numerical samples of rocks with the same diameter and different height-to-diameter 


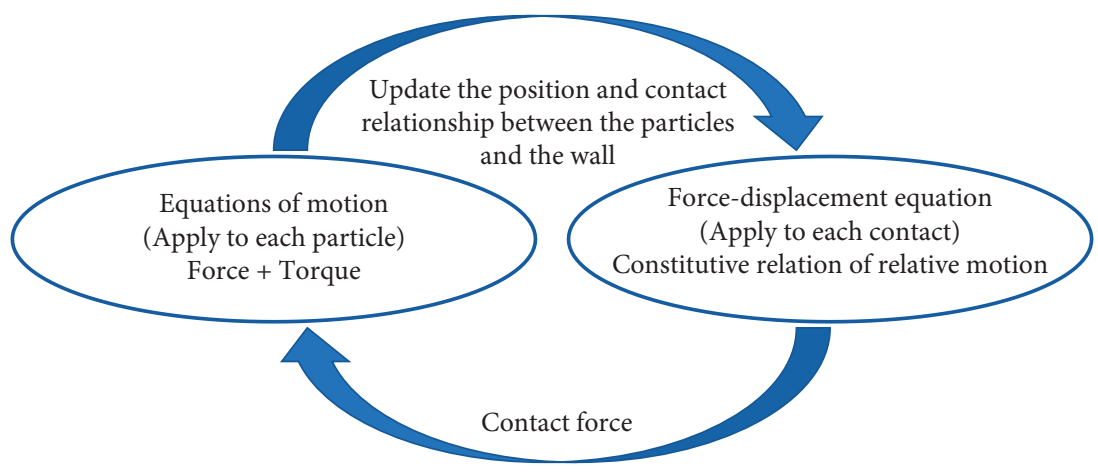

Figure 1: Calculation cycle process of PFC2D.

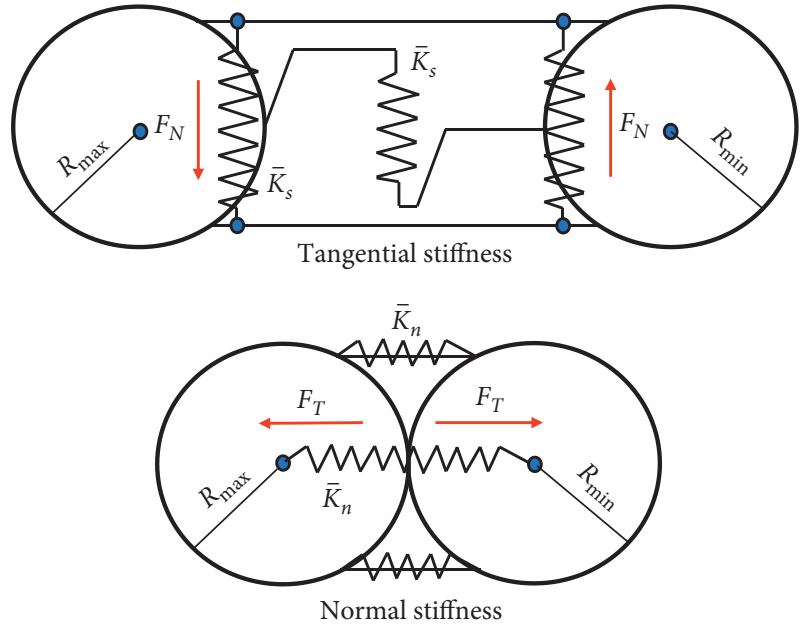

FIGURE 2: Sketch map of parallel bond model.

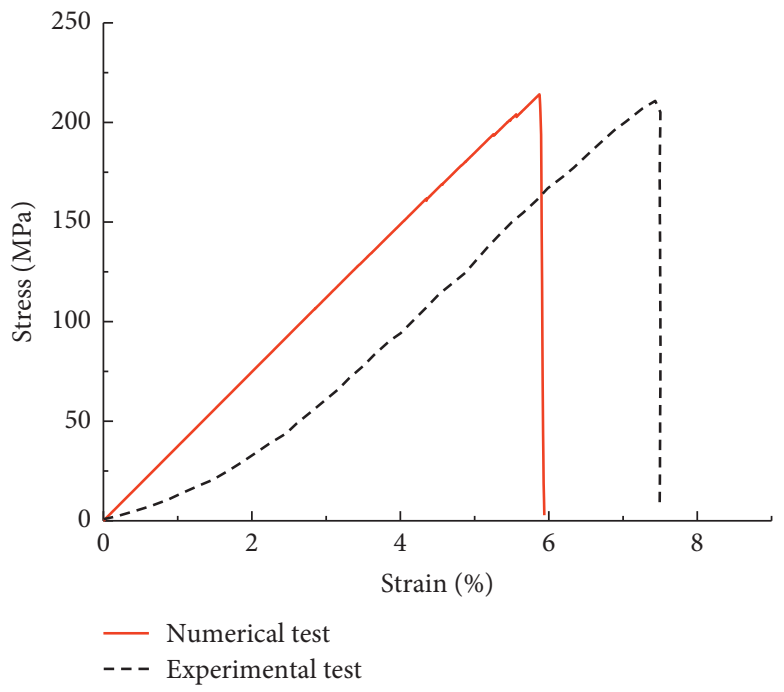

FIGURE 3: Sandstone values and indoor stress-strain curve.
TABle 1: Meso-mechanical parameters of sandstone physical mechanics.

\begin{tabular}{lc}
\hline Parameter & Magnitude \\
\hline Minimum particle size $(\mathrm{mm})$ & 0.3 \\
Particle size ratio & 1.66 \\
Density $\left(\mathrm{kg} \mathrm{m}^{-3}\right)$ & 2620 \\
Particle contact modulus $(\mathrm{GPa})$ & 7.0 \\
Deformation modulus of parallel bonding $(\mathrm{GPa})$ & 60 \\
Porosity & 0.1 \\
Coefficient of friction & 0.78 \\
Tensile strength of parallel bonding $(\mathrm{MPa})$ & 58 \\
Parallel bonding cohesion $(\mathrm{MPa})$ & 128 \\
\hline
\end{tabular}

ratios are shown in Figure 5. Table 2 summarizes the mechanical parameters of coal rock in all numerical schemes, where $\sigma_{p}$ is the uniaxial compressive strength of coal rock and $E$ is elastic modulus, which is the average slope of the approximate straight line portion of the stress-strain curve, and $\varepsilon$ is the peak strain. Figure 5 and Table 2 present that (1) the stress-strain curve of numerical rock can be divided into three stages. The first stage is the elastic stage, in which the stress-strain curve presents a linear characteristic; that is, the elastic modulus of the rock remains the same throughout the

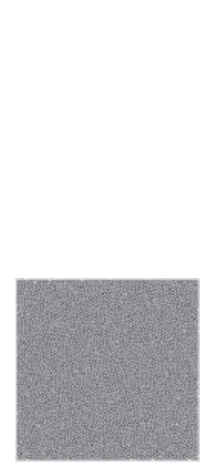

(a)

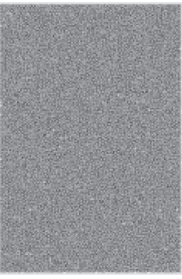

(b)

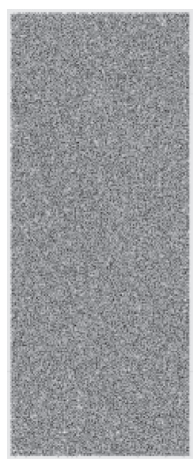

(d)
FIGURE 4: Rock specimens with different height-to-diameter ratios. (a) $K=1.0$, (b) $K=1.5$, (c) $K=2.0$, (d) $K=2.5$.

stage. The second stage is the stage of plastic deformation, which occurs at the moment before and after the peak of the rock, and the stress-strain curve shows a concave characteristic. The third stage is the residual damage stage, in which the stress-strain curve of the rock fluctuates downward. (2) With the increase in the height-to-diameter ratio $K$, the uniaxial compressive strength and peak strain of the rock 


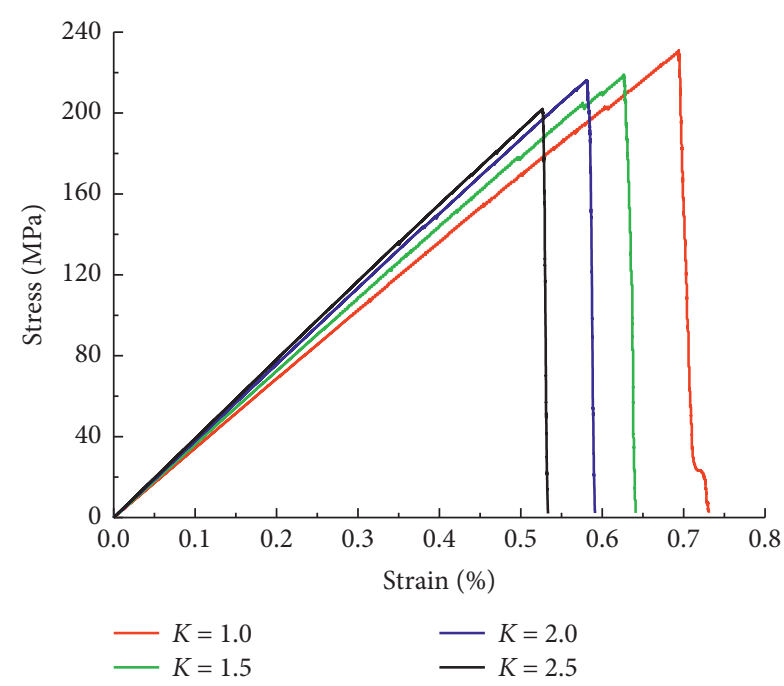

FIGURE 5: Stress-strain curves of rocks with different values of $K$.

TABLe 2: Macro mechanical parameters of rocks with different values of $K$.

\begin{tabular}{lcccc}
\hline Numerical specimen & $K$ & $\sigma_{p}(\mathrm{MPa})$ & $E(\mathrm{GPa})$ & $\varepsilon(\%)$ \\
\hline 1 & 1.0 & 230.6 & 33.1 & 0.70 \\
2 & 1.5 & 218.6 & 25.7 & 0.63 \\
3 & 2.0 & 215.5 & 36.6 & 0.58 \\
4 & 2.5 & 201.5 & 37.8 & 0.53 \\
\hline
\end{tabular}

gradually decrease; however, the elastic modulus gradually increases. When $K=1.0$, the uniaxial compressive strength of the rock is $230.6 \mathrm{MPa}$, the peak strain is $0.70 \%$, and the elastic modulus is $33.1 \mathrm{MPa}$. When $K=1.5$, the uniaxial compressive strength of the rock is $218.6 \mathrm{MPa}$, the peak strain is $0.63 \%$, and the elastic modulus is $35.7 \mathrm{MPa}$. When $K=2.0$, the uniaxial compressive strength of the rock is $215.5 \mathrm{MPa}$, the peak strain is $0.58 \%$, and the elastic modulus is $36.6 \mathrm{MPa}$. Finally, when $K=2.5$, the uniaxial compressive strength of the rock is $201.5 \mathrm{MPa}$, the peak strain is $0.53 \%$, and the elastic modulus is $37.8 \mathrm{MPa}$.

At the same time, the rock failure modes with different height-to-diameter ratios exhibit different characteristics due to the friction between the particles and the particles and the loading wall (Figure 6). When height-to-diameter ratio $K$ is 2.5 , the rock cracks are mainly concentrated at the upper and lower ends of the specimen, which are approximately symmetrical at the center of the specimen, and the failure cracks form parallel lines. When $k$ is 2.0 , the rock failure mode is inclined through the split. For $k$ is 1.5 , the failure of the rock is mainly concentrated at the lower unloaded end, extending upward to form a mountain-shaped split failure. When $k$ is 1.0, it shows the characteristics of global columnar failure.

3.2. Influence of Rock Size on Acoustic Emission Characteristics. Along with the three stages of stress-strain curve, the acoustic emission characteristic curve of rock is also divided into three stages (Figures 7 and 8 ). The first stage corresponds to the elastic stage of the stress-strain curve of

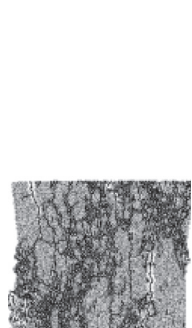

(a)

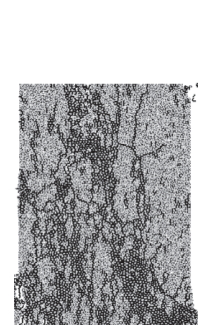

(b)

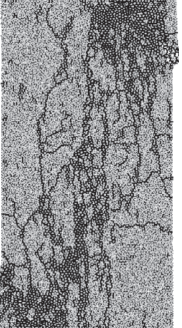

(c)

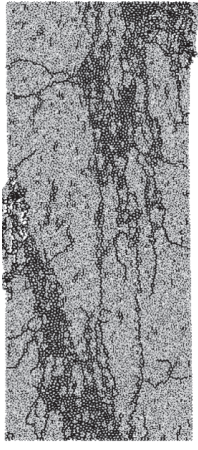

(d)
Figure 6: Failure modes of rocks with different aspect ratios. (a) $k=1.0$, (b) $k=1.5$, (c) $k=2.0$, (d) $k=2.5$.

rock. Noteworthy, the amount of acoustic emission generated in this stage is very small. On the one hand, the numerical rock does not undergo initial damage; on the other hand, the damage of the rock in the elastic stage is very small and almost no damage occurs, which can be denoted as the zero number stage of acoustic emission. The second stage corresponds to the plastic deformation stage of the stressstrain curve of the rock. Clearly, the amount of acoustic emission increases slowly at this stage; thus, this stage is called the slow increase of acoustic emission stage. The third stage corresponds to the residual damage stage of the stressstrain curve of rock. In this stage, both the amount and intensity of acoustic emission increase suddenly; thus, it is called the rapid increase stage of acoustic emission.

The established particle flow model is a $2 \mathrm{D}$ scale and the initial damage of the rock is not taken into account; therefore, the compaction and closing characteristics of the rock material are not particularly obvious. Noteworthy, the number of acoustic emission impacts in the elastic stage is zero or very few. Moreover, the effect of acoustic emission characteristics is small. However, in the plastic deformation stage and the residual damage stage, the scale effect of the rock slightly influences the acoustic emission characteristics, as follows: (1) the maximum number of impacts (intensity) affecting acoustic emission. For example, with the increase of rock aspect ratio, the maximum number of impacts of acoustic emission increases. When $K$ is 1.0 , the number of acoustic emission impacts of the rock is 19 ; when $K$ is 1.5 , the number of these impacts of the rock is 24 ; when $K$ is 2 , the number of acoustic emission impacts is 26 ; and when $K$ is 2.5 , the number of these impacts of the rock is 31. (2) The strain range that affects the impact of strong acoustic emission. With the increase in the height-to-diameter ratio of the rock, the strong strain range of acoustic emission decreases. When $K$ is 1.0 , the strain range of strong acoustic emission is about $0.026 \%$; when $K$ is 1.5 , the strain range is about $0.019 \%$; when $K$ is 2.0 , the strain range of strong acoustic emission is about $0.016 \%$; and for $K$ equaling 2.5 , the strain range of strong acoustic emission is about $0.009 \%$. (3) The time when the maximum acoustic emission impact occurs. With the increase in the height-to-diameter ratio of the rock, the time during which the maximum acoustic emission impact occurs gradually increases. For instance, when $K$ is 1.0, the maximum time for acoustic emission impact is 


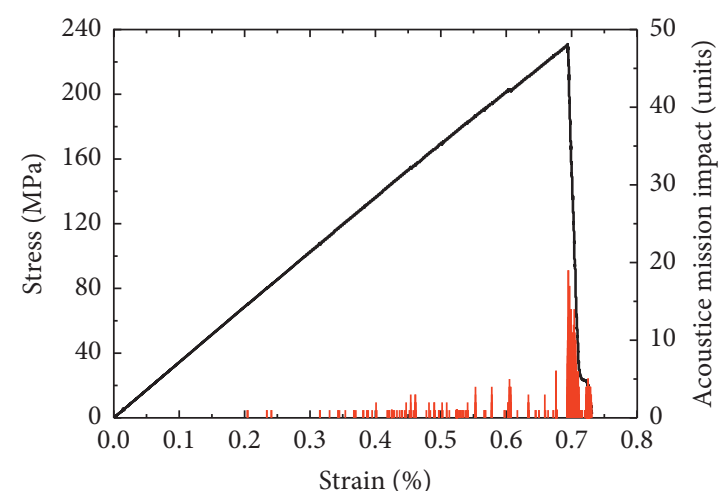

- Stress

Acoustic emission impact

(a)

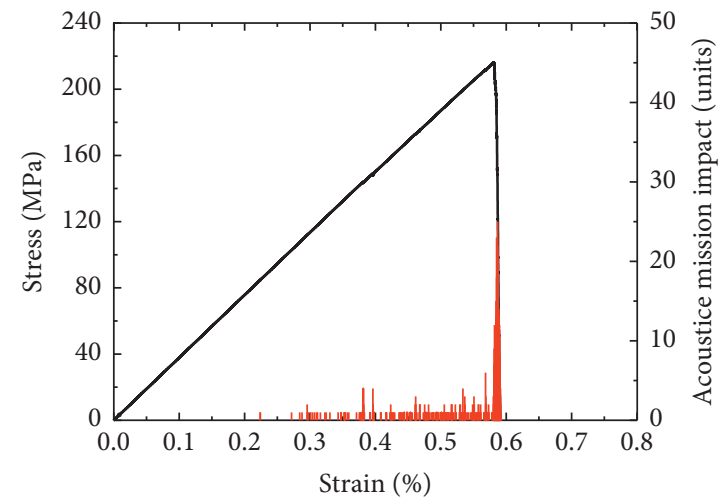

- Stress

Acoustic emission impact

(c)

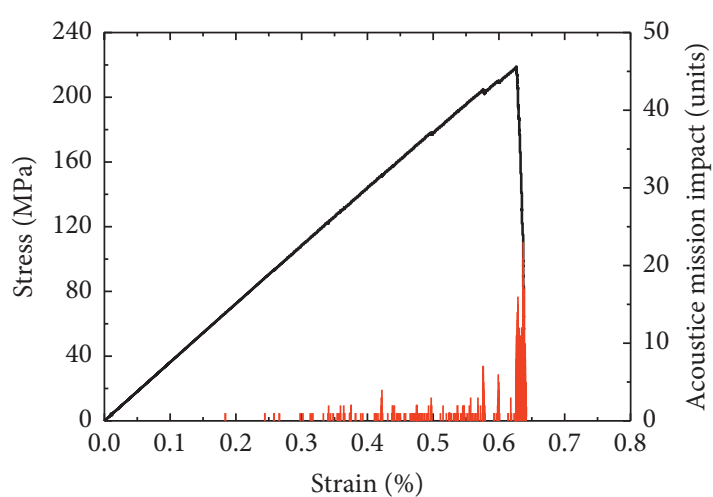

Stress

Acoustic emission impact

(b)

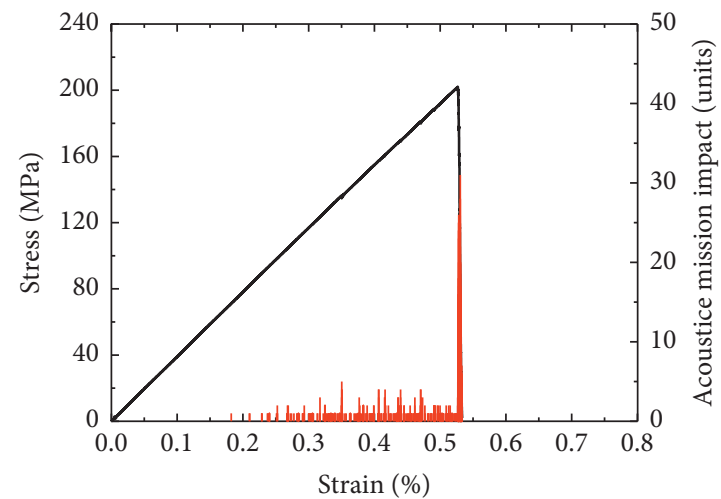

Stress

Acoustic emission impact

(d)

FIGURE 7: Stress-strain-acoustic emission characteristic curves of rock specimens with different values of $K$. (a) $K=1.0$, (b) $k=1.5$, (c) $k=2.0$, (d) $k=2.5$.

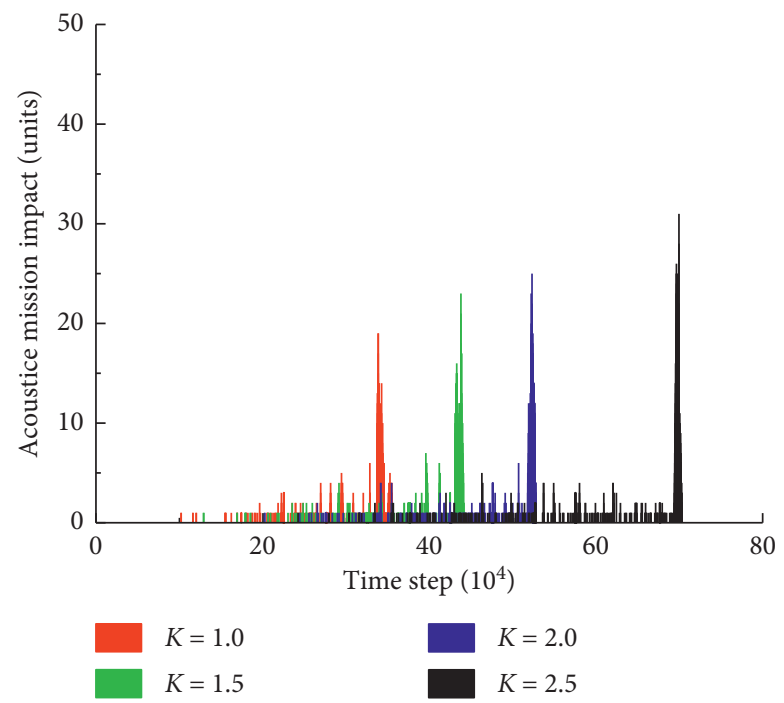

FIgURE 8: Acoustic emission-time step characteristic curves of rock specimens with different values of $K$. 
339,130 ; when $K$ is 1.5 , the maximum time for acoustic emission impact is 438,294; when $K$ is 2 , the maximum time for acoustic emission impact is 523,076; and when $K$ is 2.5 , the maximum time for acoustic emission impact is 697,324 .

In practice, the stability of rock can be monitored according to these characteristics so as to prevent and control rock geological disasters.

\section{Analysis of Damage Evolution Characteristics of Rocks with Different Values of $K$}

4.1. Rock Damage Constitutive Model Based on Acoustic Emission Characteristics. Kachanov [31] defined the damage variable as

$$
D=\frac{A_{d}}{A}
$$

where $A_{d}$ is the section area of material damage at a certain time and $A$ is the sectional area at the time when the material is initially free from damage.

It is assumed that the cumulative amount of acoustic emission at the time when the lossless section area $A$ of the rock specimen completely loses its bearing capacity is $S$; then, the cumulative count $S_{w}$ of acoustic emission at the failure of rock particles per unit area is

$$
S_{w}=\frac{S}{A} .
$$

When the section damage reaches $A_{d}$, the cumulative count $S_{d}$ is

$$
S_{d}=S_{w} A_{d}=\frac{S}{A} A_{d}
$$

Therefore,

$$
D=\frac{S_{d}}{S}
$$

The constitutive model of rock uniaxial compression damage based on acoustic emission characteristics and the principle of strain equivalence [32] is represented as follows:

$$
\sigma=E \varepsilon(1-D)=E \varepsilon\left(1-\frac{S_{d}}{S}\right)
$$

The constitutive model based on the fitting of acoustic emission parameters can better reflect the stress-strain characteristics of rock, which also shows that the acoustic emission parameters are reasonable as the damage factors of rock (Figure 9).

4.2. Damage Evolution Law of Rock with Different Scales. With the increase of strain, the characteristic curves of rock damage variables can also be divided into three stages (Figure 10). Corresponding to the elastic stage, plastic deformation stage, and residual damage stage of the stressstrain curve of the rock, the damage variable of the rock can

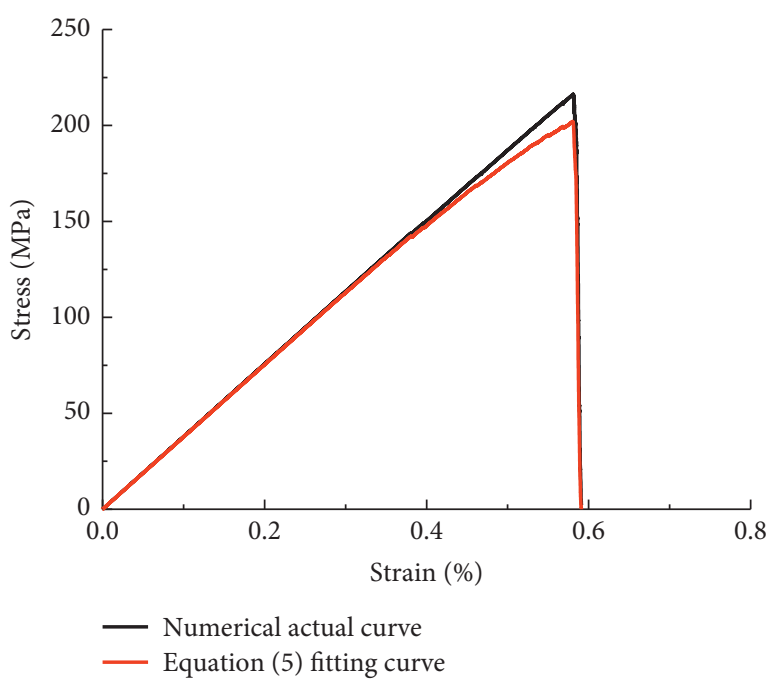

FIGURE 9: Fitting stress-strain curve of standard size rock.

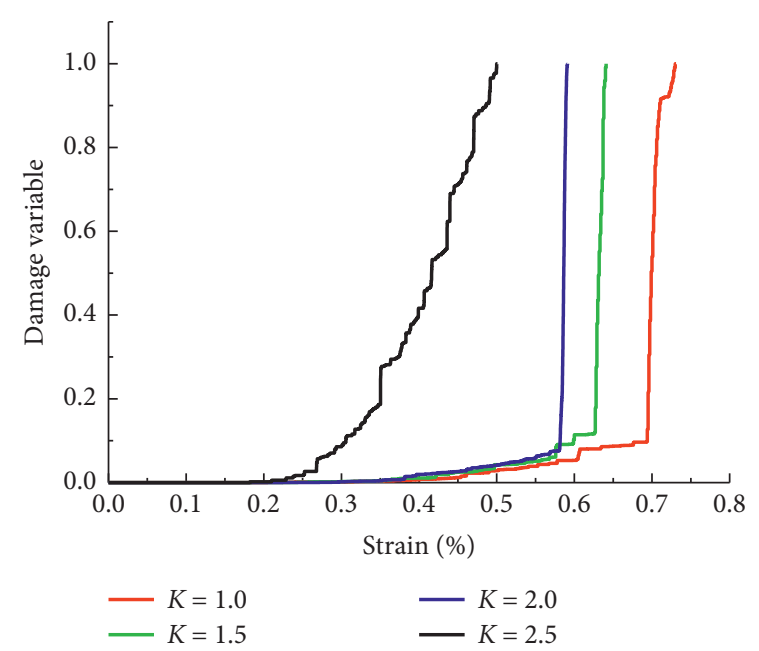

FIgURE 10: Strain-damage variable characteristic curve of rock numerical specimen.

be divided into three stages: when the damage variable is in zero stage, it increases slowly and the damage accelerates. The $K$ has little effect on the zero damage stage of rock; however, the damage slowly increases and accelerates. For samples with $K$ less than 2.0, the increase in the rate of rock damage variable is basically the same, but for $K$ equaling 2.5 , it is relatively large. For the damage acceleration stage, when $K$ is between 1.0 and 2.0, the slope of the damage acceleration development stage is almost vertical, while for rock samples with $K$ equal to 2.5 , the slope of the damage development stage is relatively low. This indicates that when $K$ is less than 2.0, the damage evolution law of rocks shows some similarities. In contrast, when $K$ is greater than 2.0, the damage evolution law shows a characteristic of slowing down in the damage acceleration phase. Although the damage evolution law is similar when $K$ is 1.0 to 2.0, some differences are also observed. With the decrease of $K$, the strain value of the damage acceleration increases gradually. 


\section{Conclusions}

In this study, the damage constitutive model of rock was established and the damage evolution characteristics of rock with different height-to-diameter ratios were analyzed. The results indicated that the stress-strain curve of numerical rock can be divided into three stages: elastic deformation, plastic deformation, and residual damage. With the increase of $K$, the uniaxial compressive strength and peak strain of the rock gradually decrease, but the elastic modulus gradually increases.

Owing to the frictional force inside the particles and between the particles and the loading wall, the rock failure modes exhibit different characteristics under different height-to-diameter ratio conditions. When $K$ is 2.5 , the rock cracks are mainly concentrated on the upper and lower ends of the test piece and are approximately symmetrical to the center of the test piece. Thus, the cracks are broken into parallel lines. When $K$ is 2.0 , the rock failure pattern is inclined through splitting. When $K$ is 1.5 , the failure of the rock is mainly concentrated at the lower unloaded end, extending upward to form a mountain-shaped split failure. However, for $K$ equaling 1.0, the rock crack shows global columnar destruction characteristics.

Accompanying the characteristics of the stress-strain curve, the acoustic emission characteristic curve of rock is correspondingly divided into three stages: zero number of acoustic emission, slow increase of acoustic emission, and rapid increase of acoustic emission. The scale effect exhibits slight influence on the acoustic emission characteristics during the elastic phase. However, in the stage of plastic deformation and residual damage, the scale effect of rock shows a certain effect on the characteristics of acoustic emission. With the increase of the rock aspect ratio, the maximum number of acoustic emission impacts increases, the range of strong strain of acoustic emission decreases, and the maximum time of acoustic emission impacts increases gradually.

The damage variable of rock can be divided into three stages: the damage variable in zero stage, slowly increasing stage of the damage variable, and the damage accelerating development stage. The ratio of height-to-diameter has little effect on the zero damage stage of rock, but the damage slowly increases and accelerates. The damage evolution law is similar when $K$ is 1.0 to 2.0, but when $K$ is greater than 2.0, the damage evolution law shows the characteristics of slowing down in the acceleration phase.

\section{Data Availability}

The data are available and explained in this article; readers can access the data supporting the conclusions of this study. All data are available within the article and also from the corresponding author upon request.

\section{Conflicts of Interest}

No conflicts of interest exist in the submission of this manuscript, and the manuscript is approved by all authors for publication. The authors would like to declare that the work described herein is original research that has not been previously published.

\section{Acknowledgments}

The authors greatly acknowledge the financial support from the Research and Development Project of Guizhou University of Engineering Science (Grant No. G2018016), Youth Science and Technology Talent Growth Project of Guizhou Provincial Education Department ([2020]155), and the Key Laboratory of Rock Mechanics and Geohazards of Zhejiang Province (PCMGH-2016-Z-02 and ZJRMG-2019-10).

\section{References}

[1] M. C. He, H. P. Xie, and S. P. Peng, "Study on rock mechanics in deep mining engineering," Chinese Journal of Rock Mechanics and Engineering, vol. 24, no. 16, pp. 2803-2813, 2005.

[2] G. T. Huang, Research on the Prediction and Prevention of Rockburst of Cuihuashan Super Long Tunel in Qinling Mountain, Xi'an University of Architecture and Technology, Xi'an, China, 2013.

[3] D. Liu, Z. Gu, R. Liang et al., "Impacts of pore-throat system on fractal characterization of tight sandstones," Geofluids, vol. 2020, no. 9, 17 pages, Article ID 4941501, 2020.

[4] X. Wang, C. Liu, S. Chen, L. Chen, K. Li, and N. Liu, "Impact of coal sector's de-capacity policy on coal price," Applied Energy, vol. 265, Article ID 114802, 2020.

[5] B. Chen, S. C. Zhang, Y. Y. Li, Z. K. Li, and H. J. Zhou, "Physical simulation study of crack propagation and instability information discrimination of rock-like materials with faults," Arabian Journal of Geosciences, vol. 13, p. 966, 2020.

[6] C. Zhu, M. He, M. Karakus, X. Cui, and Z. Tao, "Investigating toppling failure mechanism of anti-dip layered slope due to excavation by physical modelling," Rock Mechanics and Rock Engineering, vol. 53, no. 11, pp. 5029-5050, 2020.

[7] G. Feng, X. C. Wang, M. Wang, and Y. Kang, "Experimental investigation of thermal cycling effect on fracture characteristics of granite in a geothermal-energy reservoir," Engineering Fracture Mechanics, vol. 235, Article ID 107180, 16 pages, 2020.

[8] H. Y. Pan, D. W. Yin, N. Jiang, and Z. G. Xia, "Crack initiation behaviors of granite specimens containing crossing-doubleflaws with different lengths under uniaxial loading," Advances in Civil Engineering, vol. 2020, Article ID 8871335, 13 pages, 2020.

[9] J. Xu, A. Haque, W. Gong et al., "Experimental study on the bearing mechanisms of rock-socketed piles in soft rock based on micro X-ray CT analysis," Rock Mechanics and Rock Engineering, vol. 53, no. 8, pp. 3395-3416, 2020.

[10] G. C. Shi, X. J. Yang, H. C. Yu et al., "Acoustic emission characteristics of creep fracture evolution in double-fracture fine sandstone under uniaxial compression," Engineering Fracture Mechanics, vol. 210, pp. 13-28.

[11] C. D. Su and Z. H. Zhang, "Analysis of plastic deformation and energy property of marble under pseudo-triaxial compression," Chinese Journal of Rock Mechanics and Engineering, vol. 27, no. 2, pp. 273-280, 2008.

[12] J. Wang, Y. Zhang, Z. Qin, S. Song, and P. Lin, “Analysis method of water inrush for tunnels with damaged waterresisting rock mass based on finite element method-smooth 
particle hydrodynamics coupling," Computers and Geotechnics, vol. 126, Article ID 103725, 2020.

[13] J. T. Chen, J. H. Zhao, S. C. Zhang, Y. Zhang, F. Yang, and M. Li, "An experimental and analytical research on the evolution of mining cracks in deep floor rock mass," Pure and Applied Geophysics, vol. 177, pp. 5325-5348, 2020.

[14] C. Zhu, Z. G. Tao, S. Yang, and S. Zhao, "V shaped gully method for controlling rockfall of high-steep slope in China," Bulletin of Engineering Geology and the Environment, vol. 78, no. 4, pp. 2731-2747, 2019.

[15] C. Zhu, X. D. Xu, and W. R. Liu, "Softening damage analysis of gypsum rock with immersion time based on laboratory experiment," IEEE Access, vol. 7, pp. 125575-125585, 2019.

[16] H. M. Zhou and X. H. Kong, "Problems and countermeasures on parameter selection of rock mechanics in water conservancy and hydropower projects," Journal of Yangtze River Scientific Research Institute, vol. 23, no. 4, pp. 36-40, 2006.

[17] L. Wang, D. Sun, and X. Zheng, "Size effect experiment of uniaxial compressive strength of three typical rocks," Journal of Geomechanics, vol. 23, no. 2, pp. 327-333, 2017.

[18] Z. Z. Liang, Y. B. Zhang, and S. B. Tang, "Size effect of rock messes and associated representative element properties," Chinese Journal of Rock Mechanics and Engineering, vol. 32, no. 6, pp. 1157-1166, 2013.

[19] S. Yang, W. Xu, and C. Su, "Study on statistical damage constitutive model of rock considering scale effect," Chinese Journal of Rock Mechanics and Engineering, vol. 24, no. 24, pp. 4484-4490, 2005.

[20] H. Zhang, Z. L. Wang, and Z. T. Lu, "Size effect of mechanical properties of granite under cyclic impact loading," HydroScience and Engineering, vol. 2, pp. 107-115, 2020.

[21] C. J. Hong, M. Huang, and C. C. Xia, "Size effect study on anisotropic variation coefficient of rock joint," Rock and Soil Mechanics, vol. 41, no. 7, 2020.

[22] W. B. Fu, "Experimental study on size effect of uniaxial compressive strength of rock with different height-diameter ratio," Resources Environment \& Engineering, vol. 33, no. 2, pp. 232-234, 2019.

[23] J. P. Li, "Application of AE techniques in mining engineering," Industrial Safety and Dust Control, vol. 1, pp. 32-25, 2000.

[24] Y. C. Ding, "Discussion on paleostress measurement by AE method," Journal of Geomechanics, vol. 6, no. 2, pp. 45-52, 2000.

[25] S. F. Liu, "The up-to-date methods for acoustic emission source recognition," Nonde Structive Testing, vol. 24, no. 12, pp. 534-538, 2002.

[26] K. Zhao, D. Q. Yan, and C. H. Zhong, "Comprehensive analysis method and experimental vertification for in-situ stress measurement by acoustic emission tests," Chinese Journal of Geotechnical Engineering, vol. 34, no. 8, pp. 1403-1411, 2012.

[27] X. D. Zhao and B. Chen, "Study of micro-seismic engineering applications," Chinese Journal of Rock Mechanics and Engineering, vol. 21, no. a02, pp. 2609-2612, 2002.

[28] Q. Meng, H. Wang, M. Cai, W. Xu, X. Zhuang, and T. Rabczuk, "Three-dimensional mesoscale computational modeling of soil-rock mixtures with concave particles," Engineering Geology, vol. 277, Article ID 105802, 2020.

[29] B. Q. Hao, C. S. Zhang, and C. L. Wang, "Method for determining micro-parameter of rock PFC2D model," Coal Science and Technology, 2020.

[30] W. R. Liu, Z. Q. Yin, and A. Y. Yuan, "Particle-discrete-element-method-based research on acoustic emission characteristics and energy evolution laws of surrounding rock in different Lithologic roadway," Journal of Mining \& Safety Engineering, vol. 34, no. 2, pp. 363-370, 2017.

[31] L. M. Kachanov, "Time rupture process under creep conditions," Izvestia Akademii Nauk SSSR, Otdelenie Tekhnicheskich Nauk, vol. 12, no. 8, pp. 26-31, 1958.

[32] J. Lemaitre, J. P. Sermage, and R. Desmorat, "A two scale damage concept applied to fatigue," International Journal of Fracture, vol. 97, no. 1-4, pp. 67-81, 1999. 